\title{
Management of the most common ENT presentations
}

Articles in this issue of the JLO provide insight into the management of some of the most common caseload seen in ENT practice. Firstly, there are the many patients who present to ENT clinics with medically unexplained symptoms. These patients form a large part of out-patient workload and include those with symptoms such as dizziness, tinnitus, blocked ears, catarrh, atypical facial pain, throat lumps and dysphonia. These are patients with symptoms but with no demonstrable pathology on examination or investigation. In their excellent review of these conditions, Ullas and colleagues ${ }^{1}$ stress the importance of consultations that recognise the symptoms and their impact, rather than adopting a purely dismissive stance. There is now much more of an emphasis on psychological factors due to an association with anxiety and depression.

Another article considers the management of epistaxis in anticoagulated patients, a condition which now constitutes the most frequent cause of emergency admission in UK ENT units. These patients often pose significant management challenges, particularly in regard to their anticoagulant medication. ${ }^{2}$ Biggs and colleagues $^{3}$ propose a treatment algorithm which if implemented would help standardise the management of epistaxis patients, and should reduce morbidity associated with unnecessary routine discontinuation of such medication.

Another recurrent theme in the context of hospitalacquired infections is the optimum method of disinfection of flexible fibre-optic endoscopes. This is a particular problem in the out-of-hours setting when normal back-up facilities for disinfection are not available. In their survey, Radford and colleagues ${ }^{4}$ found that there was widespread non-compliance with 2005 ENT-UK guidelines, and they point out the need for urgent action to ensure best practice. Depressingly, this study showed that little had improved in the 10 years since a previous assessment of UK practice. ${ }^{5}$

ROBIN YOUNGS EDWARD FISHER

Editors

References

1 Ullas G, McClelland L, Jones NS. Medically unexplained symptoms and somatisation in ENT. $J$ Laryngol Otol 2013;127: $452-7$

2 Smith J, Siddiq S, Dyer C, Rainsbury J, Kim D. Epistaxis in patients taking oral anticoagulant and antiplatelet medication: prospective cohort study. J Laryngol Otol 2011;125:38-42

3 Biggs TC, Baruah P, Mainwaring J, Harries PG, Salib RJ. Treatment algorithm for oral anticoagulant and antiplatelet therapy in epistaxis patients. J Laryngol Otol 2013;127:483-8

4 Radford D, Unadkat SN, Rollin M, Tolley NS. Disinfection of flexible fibre-optic endoscopes out-of-hours: confidential telephone survey of ENT units in England - 10 years on. J Laryngol Otol 2013;127:489-93

5 Kanagalingam J, Zainal A, Georgalas C, Paun S, Tolley NS. The disinfection of flexible fibre-optic nasendoscopes out-of-hours: confidential telephone survey of ENT units in England. J Laryngol Otol 2002;116:817-22 